\title{
Improved performance of open volumetric receivers by employing an external air return system
}

\author{
Hannes Stadler ${ }^{\mathrm{a}, *}$, Arne Tiddens ${ }^{\mathrm{a}}$, Peter Schwarzbözl ${ }^{\mathrm{b}}$, Felix Göhring ${ }^{\mathrm{a}}$, Torsten Baumann ${ }^{\mathrm{a}}$, \\ Johannes Trautner ${ }^{c}$ \\ ${ }^{a}$ DLR Institute of Solar Research, Prof.-Rehm-Straße 1, 52428 Jülich, Germany \\ ${ }^{\mathrm{b}}$ DLR Institute of Solar Research, Linder Höhe, 51147 Köln, Germany \\ ${ }^{\mathrm{c}}$ Kraftanlagen München GmbH, Ridler Straße 31 c, 80339 München, Germany
}

\section{A R T I C L E I N F O}

Article history:

Received 26 April 2016

Received in revised form 5 July 2017

Accepted 17 July 2017

Keywords:

Open volumetric receiver

Air return ratio

Tracer gas measurement

External air return

\begin{abstract}
A B S T R A C T
In solar central receiver power plants open volumetric receivers using air as heat transfer fluid are an alternative to the currently predominant receiver types, namely salt and steam receivers. In order to improve their competitiveness, the receiver performance has to be improved. In the current study an external air return system has been integrated in the Solar Tower Jülich and its influence on power plant performance has been investigated. With this system, the parasitic losses caused by the fans are reduced by up to $34 \%$. The measured air return ratio is mostly unaffected, but the current data suggest, that the internal and external convective losses of the receiver are reduced when an external air return system is applied. A positive influence of the total mass flow on the air return ratio has been identified for the current data while other parameters like the return air temperature turned out to be less significant.
\end{abstract}

(C) 2017 Elsevier Ltd. All rights reserved.

\section{Introduction}

Most solar central receiver power plants in operation, under construction, or in development make use of either molten salt or steam receivers. As an alternative to these technologies open volumetric receivers using air as heat transfer fluid can be used. The advantage of open volumetric receivers is their relative technical simplicity since atmospheric air as heat transfer fluid is absolutely harmless and no care has to be taken to prevent freezing (as in salt receivers) or to stabilise the boiling point (as in steam receivers). However, up to now no commercial plants with this receiver type are in operation or under construction. Research is still needed to increase the efficiency of the receiver and the air cycle so that the competitiveness of this technology is improved. Among the approaches to increase the efficiency is an enhancement of the air return ratio so that thermal losses in the receiver are reduced.

\section{State of the art}

A very good overview on the development of open volumetric receivers was given by Ávila-Marín (2011). The main focus of the

\footnotetext{
* Corresponding author.

E-mail address: hannes.stadler@dlr.de (H. Stadler).
}

development in the past years has been the absorber structure itself. Different types like honeycomb structures, foams, or wire meshes (Fend et al., 2004; Schwarzbözl et al., 2011) and more recently also printed structures have been investigated (Capuano et al., 2015). A general concern persists regarding flow instabilities in the absorber structure which could lead to failure of the receiver, Kribus et al. (1996). However, it has been shown by Pitz-Paal et al. (1997) or later by Becker et al. (2006) that these instabilities can be prevented by a careful design of the absorber. So far no failure of the so-called HiTRec ceramic absorber structure caused by flow instabilities has been observed neither in large-scale tests during development (Hoffschmidt et al., 2003) nor during operation in the Solar Tower Jülich, which is operational since 2009.

Up to now only two solar tower power plants with open volumetric receiver are in operation which primarily serve as demonstration and development platform. One of them is located in Jülich (Germany) where the current investigation is carried out, the other one has been built thereafter in Daegu (Korea), Jang et al. (2012).

The basic design of the Solar Tower Jülich is shown in Fig. 1, a more detailed description was given by Koll et al. (2009). The receiver is centred at about $55 \mathrm{~m}$ height and has an aperture of approximately $23 \mathrm{~m}^{2}$. The air that is heated in the receiver (1) is used to produce steam for the turbine $\left(8,1.5 \mathrm{MW}_{\mathrm{e}}\right)$ or is stored in the thermal energy storage (7) and is thereafter returned to the receiver 


\section{Nomenclature}

$\alpha \quad$ significance level

$\dot{m}_{b}^{\prime} \quad$ massflow fraction through external air system bottom

$\dot{m}_{E}^{\prime} \quad$ massflow fraction through external air system east

$\dot{m}_{s}^{\prime} \quad$ massflow fraction through stack

$\dot{m}_{W}^{\prime} \quad$ massflow fraction through external air system west

$\dot{m}_{t} \quad$ total massflow

$\dot{m}_{r, i} \quad$ massflow of return air being sucked back in

$A R R_{e} \quad$ air return ratio based on enthalpy flows

$A R R_{S} \quad$ air return ratio based on substance

$A R R_{e, \text { external }}$ air return ratio based on temperature in front of absorber $c_{i}, c_{i j} \quad$ regression coefficients

$T_{O} \quad$ outlet temperature of return air

$T_{\infty} \quad$ ambient temperature

$T_{a b s} \quad$ air temperature after absorber

$T_{I} \quad$ air temperature right in front of absorber

$T_{r} \quad$ temperature of return air

$T_{S R, i} \quad$ temperature of subreceiver $i$

$U \quad$ internal heat transfer in absorber

HiTRec High Temperature Receiver

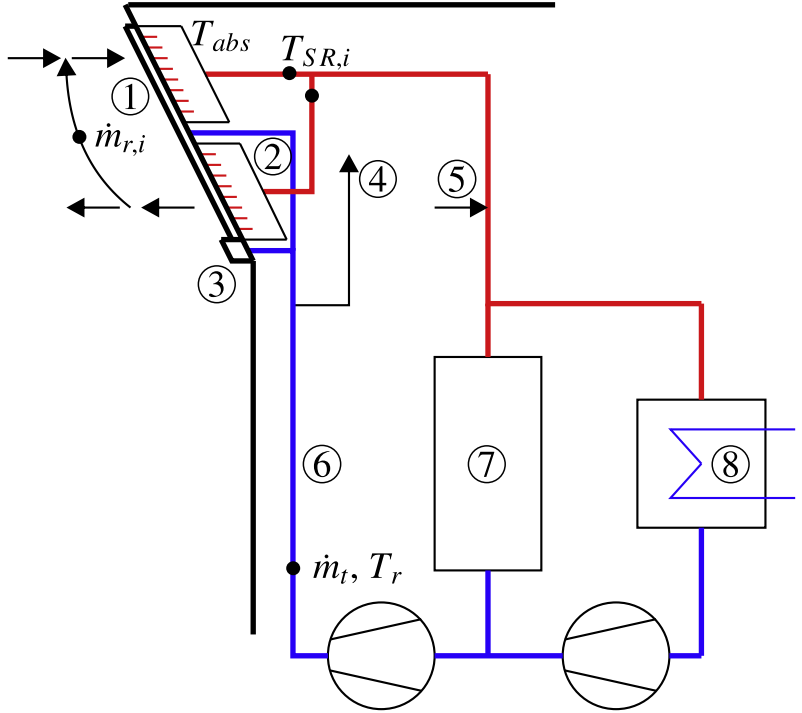

Fig. 1. Basic design of a central receiver solar power plant with open volumetric receiver, 1: receiver, 2: conventional air return system, 3: external air return system, 4: stack, 5: helium injection, 6: helium measurement position, 7: thermal energy storage, 8 : heat recovery steam generator.

in order to recycle its residual heat. Moreover, it is also used to cool the receiver metal support structure to prevent overheating. The air is then blown out in between individual absorber modules (each $\approx 0.02 \mathrm{~m}^{2}$ in size) as has been described by Ahlbrink et al. (2013), see also Fig. 2. This causes the returned air to mix with ambient air so that only a part of the returned air is sucked back in. The air flowing through individual absorber modules is heated to the temperature $T_{a b s}$. In a first step the air is collected in four so-called subreceivers each reaching an individual mixing temperature $T_{S R, i}$, before it is unified in a single hot air pipe.

In a study by Marcos et al. (2004) the significance of high air return ratios for the increase of the receiver efficiency was emphasised. More recently, Quinto (2016) has shown that a high air return ratio is particularly important when higher return air temperatures are beneficial for the subsequent process.

During the development phase of the HiTRec open volumetric receiver concept, Téllez et al. (2004) have investigated the air return ratio at the non-irradiated $3 \mathrm{MW}$ test receiver on the Plataforma Solar de Almería by means of an energy balance. The average air return ratio was about $50 \%$ with a wide spreading of measured values (up to $\pm 10 \%$-points). A slight increase of the air return ratio from $50 \%$ to $52 \%$ with increasing total mass flow from 1.5 to $3.0 \mathrm{~kg} /$ s had been measured. Téllez et al. (2004) considered this trend as

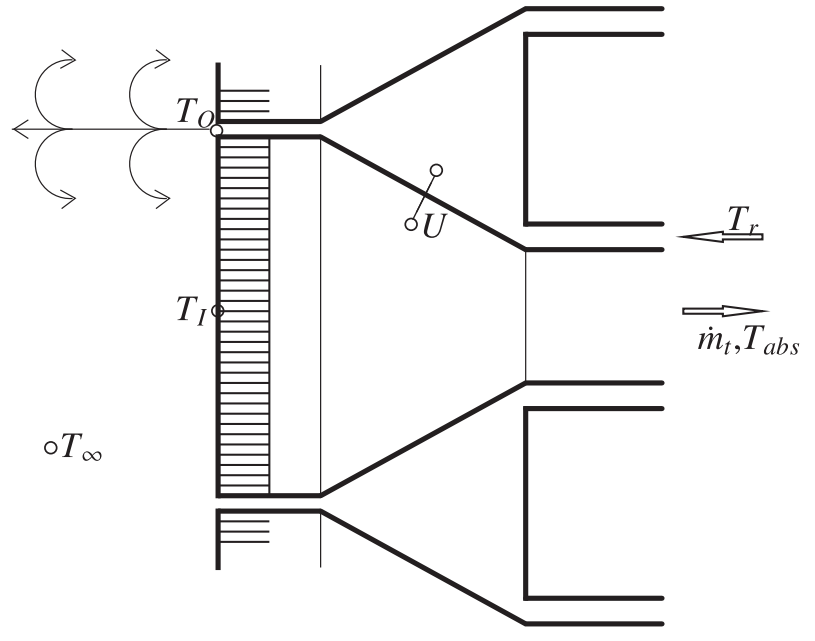

Fig. 2. Absorber with internal air return, characteristic temperatures used in Eqs. (1)-(3) are given. $U$ marks the internal heat transfer between hot air and return air.

too weak to be significant. A very weak negative trend was observed by Quinto (2016) in CFD simulations of single absorber modules.

Tiddens et al. (2017) have shown that the air return ratio for the conventional setup of the Solar Tower Jülich measured by means of a newly developed tracer gas technique is in the range of up to $69 \%$ under nominal conditions.

While in the state of the art air is returned from between the absorber modules only, it can also be returned adjacent to the absorber surface, that is from the sides or the top or bottom of the receiver. This approach, further being called external air return, is common in closed, pressurised volumetric receivers (see for example Kribus et al., 2001 or Buck et al., 2002). Anderson (2013) used an external air return in a partially closed atmospheric volumetric receiver. There, the return air is blown out through a ring in front of a concave absorber structure which is partially closed by window panes with small gaps in between. With these windows and the concave cavity design it is likely that only little losses to the ambient occur.

Instead of using window panes to cover the cavity receiver, McMillan (1984) has proposed to use an aerowindow which can help in significantly reducing convective losses. This concept has been tested for particle receivers by Tan et al. (2009) and has been investigated numerically by Flesch et al. (2016). All researchers conclude that a reduction of the convective losses can be achieved, values of up to $40 \%$ are reported. 
In their study mentioned earlier, Marcos et al. (2004) proposed to combine the return air injection through the channels between the absorbers with an injection of the return air through an outer ring adjacent to the absorber area.

External air return systems have not yet been applied at large external receivers like the Solar Tower Jülich. A direct integration of these systems seems not to be applicable since in open systems it is very likely that the air returned on the sides will be convected away from the receiver before it reaches the centre so that again not the entire return air will be sucked in. However, a combination of external air return together with the state of the art might have positive influence on the total air return ratio. Moreover, an external air return system also entails the potential for a reduction of the pressure drop. In the state of the art a large fraction of the total pressure drop in the air circuit arises due to the air being blown out between the absorber modules. This could be reduced by an external air return system.

\section{Experiments}

In the current approach a combination of a novel external air return system with the existing internal air return is investigated in order to analyse the potential for the external receiver of the Solar Tower Jülich. The focus of this investigation is the identification of parameters influencing the air return ratio as well as the parasitic power consumption of the air fans.

As mentioned afore, various methods for the determination of the air return ratio exist depending on the available measurement instrumentation. The definitions of the respective air return ratio are thereby different so that care has to be taken to use an appropriate definition when the thermal efficiency of the receiver is calculated. In this study the air return ratio is defined as the ratio of the return air which is sucked back in $\dot{m}_{r, i}$ to the total mass flow $\dot{m}_{t}$ :

$A R R_{s}=\frac{\dot{m}_{r, i}}{\dot{m}_{t}}$

In accordance with Hoffschmidt et al. (2003), the air return ratio can also be derived from an energy balance around the absorber without radiation. This air return ratio then describes the ratio of the enthalpy flow which is sucked back into the enthalpy flow blown out and thus is called air return ratio based on enthalpy flows in the following. It is only measurable when the return air is at elevated temperatures $T_{r}>T_{\infty}$ :

$A R R_{e}=\frac{T_{a b s}-T_{\infty}}{T_{r}-T_{\infty}}$.

Here, $T_{r}$ is the temperature of the return air, $T_{\infty}$ is the ambient temperature, and $T_{a b s}$ is the air temperature of the air sucked in which would be equivalent to $T_{r}$ for $100 \%$ air return. A sketch of the absorber structure with the air paths and the position of the temperatures used in the definition of the ARR is shown in Fig. 2.

It is important to note that the definitions are not interchangeable. To highlight the differences between both, a third definition based on the temperatures right in front of the absorber can be helpful:

$A R R_{e, \text { external }}=\frac{T_{I}-T_{\infty}}{T_{O}-T_{\infty}}$

$A R R_{e, \text { external }}$ according to Eq. (3) is almost equivalent to $A R R_{S}$ according to Eq. (1) and is in principle independent of the irradiation. However, $T_{O}$ and $T_{I}$ cannot effectively be measured during operation. Moreover, Eq. (3) is only valid for constant temperatures across the receiver. If temperatures vary, the enthalpy flows have to be determined instead of the temperature which is even harder to realise. The only measurable temperatures are $T_{r}$ and $T_{a b s}$ which is why the air return ratio based on entahlpy flows $A R R_{e}$ (Eq. (2)) is defined using these values.

Due to internal heat transfer in the absorber modules, marked with the thermal transmittance $U$ in Fig. 2, heat is exchanged between the return air and the incoming air so that $T_{O} \neq T_{r}$ and $T_{I} \neq T_{a b s}$. The air return ratio based on enthalpy flows $A R R_{e}$ therefore describes a combination of different effects: the air return ratio based on substance $A R R_{S}$ as well as the internal heat transfer. For negligible internal heat transfer both definitions should give similar values but with increasing internal heat transfer the air return ratio based on enthalpy flows will exceed the air return ratio by substance. Moreover, the air return ratio based on enthalpy flows is only measurable when experiments are carried out without radiation because the irradiation cannot be simultaneously measured to sufficient accuracy to be included in the energy balance. The air return ratio based on substance $A R R_{s}$ thus has a more general applicability because it is in principal independent of external effects like irradiation or the ambient temperature $T_{\infty}$ and the internal heat transfer.

\subsection{Receiver design}

For this study, the air return system of the Solar Tower Jülich has been modified allowing for up to $50 \%$ of the total air mass flow to be returned externally instead of being blown out in between absorber modules. Due to the need to cool the internal structure of the receiver, a given air flow through the receiver structure has to be retained. The fraction returned externally can be further split into fractions blown in front of the receiver from below $\left(\dot{m}_{b}^{\prime}\right)$, from the west $\left(\dot{m}_{W}^{\prime}\right)$, and the east $\left(\dot{m}_{E}^{\prime}\right)$ of the receiver. The general setup is shown in Fig. 3.

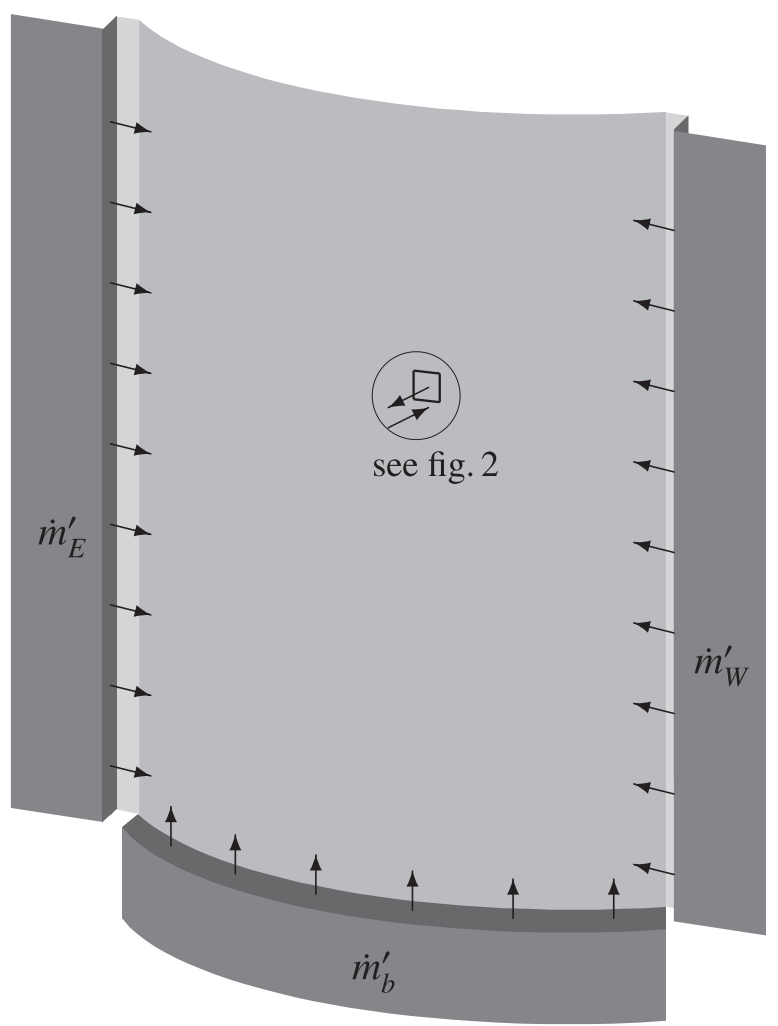

Fig. 3. Open volumetric receiver with external air return system. The absorber made of modules shown in Fig. 2 is the large light grey area in the centre. 
Next to the external air return, air can also be blown out over the stack so that the effect of the reduction of the mass flow through the receiver can be isolated from the external air return, see Fig. 1.

\subsection{Measurement technique}

For the measurement of the air return ratio a tracer-gas technique has been used which is described in detail in Tiddens et al. (2016) and Tiddens (2017). In this technique, helium is injected into the air flow and it's molar fraction is measured by means of a mass spectrometer (positions (3) and (4) in Fig. 1, respectively). When helium is injected, the measured molar fraction increases to a maximum value and after injection drops down to the ambient value again. This response to the injection is analysed and the air return ratio can be determined from the increasing slope as well as the decreasing slope separately giving two independent results for every injection. With this technique a much higher accuracy of about $\pm 0.5 \%$ can be achieved compared to calculations based on an energy balance which are very sensitive to temperature and mass flow measurement errors.

\subsection{Design of experiments}

The air return ratio is affected by many parameters of which the most important are expected to be the air mass flow, the split fractions of the mass flow, the return air temperature, the irradiation, and external wind conditions. Up to now no information has been available on the true influence of these parameters except for the faint indication of a positive influence of the total mass flow by Téllez et al. (2004) so that one focus of this study was to identify those parameters which exert considerable influence on the air return ratio. Due to the wide range of the parameters it is not feasible to run a full factorial set of experiments where every parameter setting is combined with all other possible settings. Therefore, a d-optimised test programme has been developed so that with a reduced number of experiments the key influencing factors can be identified. D-optimised test programmes are computer generated experimental designs trying to get the highest possible sensitivity for the regression with a minimum of necessary test runs, see NIST/SEMATECH (2016) for a more detailed description of optimisation of test programmes for statistical analysis. For this investigation focus has been on the identification of influencing parameters in general and not on finding exact relationships so that the test programme was designed for a linear regression with interactions according to the following equation:

$A R R_{s}^{2}=c_{0}+\sum_{i} c_{i} x_{i}+\sum_{i, j>i} c_{i j} x_{i} x_{j}$

The minimum number of experiments neccessary and the required parameter settings have been determined with a commercial software.

The influence of wind was not included in the design of the test plan since wind could not be set as boundary condition. Where possible, experiments were conducted with none to little wind. Moreover, in the first step experiments were also carried out without irradiation since it allows experiments to be conducted more flexible and it allows the separation of effects.

In total, 36 different combinations of the boundary conditions have been investigated whereof 26 experiments have been carried out without irradiation. With multiple measurements at a given setting altogether 134 measurements have been conducted. The settings investigated without irradiation are given in Table 1. Experiments with irradiation have been carried out within the same parameter range of the mass flows.
Table 1

Experimental settings investigated without irradiation acc.: measurement accuracy est.: estimated value, see text for explanation.

\begin{tabular}{|c|c|c|c|c|c|c|}
\hline $\begin{array}{l}\text { Unit } \\
\text { Acc. }\end{array}$ & $\begin{array}{c}\dot{m}_{t} \\
\mathrm{~kg} / \mathrm{s} \\
\pm 1 \%\end{array}$ & $\begin{aligned} & T_{r} \\
&{ }^{\circ} \mathrm{C} \\
& \pm \\
& \pm 2.5 \\
&\end{aligned}$ & $\begin{array}{c}\dot{m}_{s}^{\prime} \\
- \\
\pm 1 \%\end{array}$ & $\begin{array}{c}\dot{m}_{b}^{\prime} \\
- \\
\text { est. }\end{array}$ & $\begin{array}{c}\dot{m}_{W}^{\prime} \\
- \\
\text { est. }\end{array}$ & $\begin{array}{c}\dot{m}_{E}^{\prime} \\
- \\
\text { est. }\end{array}$ \\
\hline & 5.0 & & 0 & 0 & 0 & 0 \\
\hline & 5.0 & 17 & 0 & 0.3 & 0 & 0 \\
\hline & 5.0 & 16 & 0 & 0 & 0 & 0.3 \\
\hline & 10 & 18 & 0 & 0.2 & 0 & 0 \\
\hline & 10 & 19 & 0 & 0 & 0.3 & 0 \\
\hline & 10 & 18 & 0.32 & 0 & 0 & 0 \\
\hline & 10 & 19 & 0.23 & 0 & 0 & 0 \\
\hline & 9.9 & 116 & 0 & 0.2 & 0 & 0 \\
\hline & 9.9 & 94 & 0 & 0 & 0 & 0.2 \\
\hline & 5.0 & 96 & 0 & 0 & 0.3 & 0 \\
\hline & 5.0 & 96 & 0 & 0 & 0 & 0.3 \\
\hline & 5.0 & 77 & 0 & 0 & 0 & 0 \\
\hline & 10 & 22 & 0.11 & 0 & 0 & 0 \\
\hline & 10 & 24 & 0.21 & 0 & 0 & 0 \\
\hline & 10 & 21 & 0.30 & 0 & 0 & 0 \\
\hline & 10 & 20 & 0.41 & 0 & 0 & 0 \\
\hline & 10 & 21 & 0 & 0 & 0 & 0 \\
\hline & 10 & 22 & 0 & 0.3 & 0 & 0 \\
\hline & 5.0 & 20 & 0 & 0 & 0.3 & 0 \\
\hline & 5.0 & 18 & 0 & 0 & 0 & 0.3 \\
\hline & 5.0 & 21 & 0 & 0.3 & 0 & 0 \\
\hline & 10 & 20 & 0 & 0.2 & 0.2 & 0 \\
\hline & 10 & 21 & 0 & 0.2 & 0 & 0.2 \\
\hline & 5.0 & 20 & 0 & 0 & 0.2 & 0.2 \\
\hline & 5.0 & 18 & 0.33 & 0.2 & 0 & 0 \\
\hline & 5.0 & 20 & 0.30 & 0 & 0.2 & 0 \\
\hline
\end{tabular}

In the analysis, the statistical significance has been evaluated for all coefficients $c_{i}, c_{i j}$. Thereby the statistical significance gives the probability that the repective relationship occurs by chance. A normal distribution of the underlying parameters has been assumed. Since the measured samples represent only a small subset out of the normally distributed population, this results in a tdistribution of the measured data. Parameters with a significance level above $\alpha=0.01$ have been dropped from the analysis leaving only those in the final regression that can be considered statistically significant.

\subsection{Boundary conditions}

For the tests the appropriate parameters were set and the temperatures were allowed to reach steady state conditions. The mass flow has been regulated with the fan and is thus constant within technical limits (variations of the measured value below $2 \%$, measured with an ultrasonic flow metre with an accuracy of $\pm 1 \%$ of the measured value). The splitting of the mass flow into the external air return and the stack is achieved by setting respective valves. In the external air return system, the mass flows have not been measured separately since the length of the piping in the power plant did not allow the installation of any accurate mass flow sensors. Therefore, it has been neccessary to estimate the respective mass flow fractions. The total mass flow is known (at position (6) in Fig. 1) as well as the pressure drop provided by the fan which gives a characteristic of the receiver pressure drop as a function of the mass flow. Knowing the total mass flow and calculating the receiver mass flow (position (2)) from the characteristic, the mass flow through the external air return system (3) can be estimated. For verification, these calculations have been compared to measurements of the mass flow through the stack (4), where an additional mass flow metre had been installed. In these tests, the valve regulating the mass flow through the stack has been set in order to give the same pressure drop across the receiver at a given total mass flow as when the external air return system is used. 
Since this proceduce allows only an approximate estimation of the true massflow fraction, no intermediate values have been investigated: the valves regulating the external air have only been opened or closed completely.

The return air temperature has been measured in proximity to the fan (see also Fig. 1) with five type $\mathrm{N}$ thermocouples. Their mean value has been used for further analysis. Under steady-state conditions, heat losses in the piping are negligible so that the actual return air temperature at the receiver is only slightly lower (maximum temperature difference below $5 \mathrm{~K}$ ). In the external air return system the heat losses are larger since the insulation is not as thick. Moreover, it has not been possible to obtain fully stationary conditions in the external air return system when operating with warm return air and without irradiation at the same time. This is due to the long time needed to reach thermal equilibrium in the return air piping and the finite capacity of the heat storage which has been used in these cases. However, measurements of the air return ratio are independent of the operating temperature so that the results are only indirectly affected by reduced buoyancy effects in front of the receiver.

For the experiments every setting was held for at least $50 \mathrm{~min}$. Helium was injected twice within that time for a period of $10 \mathrm{~min}$ resulting in a total of four measurements for every setting, that is leading and trailing edge for every injection. Since the temperatures might have drifted slightly in that time, the respective mean values of the mass flows and the temperatures have been evaluated separately for every analysis.

The experiments have been carried out at the Solar Tower Jülich and thus have been exposed to the ambient so that wind gusts could have influenced the results.

\section{Results}

Data of all measurements have been used in the statistical analysis of the influencing parameters on the air return ratio whereas only subsets have been used in the analyses of the parasitic losses and the energetic benefits.

\subsection{Air return ratio}

After dropping out statistically insignificant parameters, the regression over all experiments carried out without irradiation exhibits four parameters and one additional interaction next to a constant value. The found regression is defined by following equation:

$A R R_{s}^{2}=c_{0}+c_{1} \cdot \dot{m}_{t}+c_{2} \cdot T_{r}+c_{3} \cdot \dot{m}_{s}+c_{4} \cdot \dot{m}_{W}+c_{5} \cdot \dot{m}_{t} \cdot T_{r}$.

The coefficients of this equation are given in Table 2 together with the evaluated standard deviation. Although the evaluated trends are statistically significant, the respective standard deviations could be improved. However, in order to improve the regression, many more experiments would be necessary to allow for higher order regressions with more parameters. Since every single experiment used

Table 2

Coefficients of the linear regression shown in Fig. 4.

\begin{tabular}{lcc}
\hline Coefficient & Value & Standard deviation \\
\hline$c_{0}$ & $3.71 \mathrm{e}-2$ & $2.00 \mathrm{e}-2$ \\
$c_{1}$ & $3.86 \mathrm{e}-2$ & $2.25 \mathrm{e}-3$ \\
$c_{2}$ & $1.57 \mathrm{e}-3$ & $4.36 \mathrm{e}-4$ \\
$c_{3}$ & $-3.05 \mathrm{e}-1$ & $2.52 \mathrm{e}-2$ \\
$c_{4}$ & $1.57 \mathrm{e}-1$ & $4.36 \mathrm{e}-2$ \\
$c_{5}$ & $-1.47 \mathrm{e}-4$ & $5.04 \mathrm{e}-05$ \\
\hline
\end{tabular}

for the current regression took about two hours of measurement time with the complete Solar Tower Jülich, this has not been realisable. In Fig. 4 the response of the air return ratio is plotted against the four variables in blue. The shaded area in each plot highlights the $95 \%$ confidence interval (non-simultaneous). All responses have been evaluated for constant values of the respective other parameters. These constant values are shown in the plots with dashed red lines.

In the first plot (top, left), the air return ratio is plotted versus the total mass flow showing an increase of the air return ratio with increasing total mass flow. While in the base case $\left(\dot{m}_{t}=5 \mathrm{~kg} / \mathrm{s}, T_{r}=20^{\circ} \mathrm{C}, \dot{m}_{s}^{\prime}=0.0\right.$, and $\left.\dot{m}_{W}^{\prime}=0.0\right)$ the air return ratio is $49.7 \pm 1.5 \%$, it increases to $65.2 \pm 1.0 \%$ at $\dot{m}_{t}=10 \mathrm{~kg} / \mathrm{s}$.

In the second plot (top, right), a minor increase of the air return ratio with the return air temperature can be seen, it rises only to about $65.9 \pm 2.0 \%$ at $T_{r}=115^{\circ} \mathrm{C}$.

The fraction of the total mass flow going through the stack (4) in Fig. 1) has an inverse effect on the air return ratio, see bottom left in Fig. 4. At the maximum investigated fraction of 0.5 , the air return ratio drops to $52.2 \pm 1.9 \%$. With increasing mass flow fraction the confidence interval also increases because the number of experiments carried out with large stack mass flow fractions has been lower.

The last significant parameter is the mass flow fraction of the external air return in the west. It shows a slight increase of the air return ratio up to $68.7 \pm 1.8 \%$ at $\dot{m}_{W}^{\prime}=0.3$.

Not explicitly shown here but also significant is the interaction $\dot{m}_{t} \cdot T_{r}$. On the one hand this interaction causes the effect of the total mass flow to decrease with large return air temperatures and on the other hand causes the effect of the return air temperature to be increased under part load conditions.

No significance was found for the external air return mass flow fractions east and bottom nor for any other interaction between parameters.

The regression over the entire dataset including irradiation follows similar trends for the total mass flow, the return air temperature, and the stack mass flow fraction. The external air return system exhibits a slightly negative trend for $\dot{m}_{b}^{\prime}$. The linear regression also shows a decrease of the air return ratio with increasing irradiation. However, a direct comparison of experiments with and without irradiation gives a different trend. At $\dot{m}_{t}=10 \mathrm{~kg} / \mathrm{s}$ the air return ratio without irradiation has been $64 \pm 2 \%$ and with irradiation $69 \pm 4 \%$ and at $\dot{m}_{t}=5 \mathrm{~kg} / \mathrm{s}$ the values have been $52 \pm 5 \%$ and $57 \pm 5 \%$, respectively.

\subsection{Parasitics}

Since the pressure drop of the return air through the receiver makes up a significant portion of the total pressure drop, a strong reduction of the power consumption with increasing external air return was expected. In Fig. 5 this relationship is shown for the stack mass flow fraction which is equivalent to the external air ratio in terms of pressure drop. The fan power consumption drops continuously with increasing external air fraction. At an external air return rate of $40 \%$ the power consumption is only $66 \%$ of the reference power consumption. The error bars shown in Fig. 5 are 95\% confidence intervals for the mass flow fraction and standard deviation for the normalised power consumption.

\subsection{Energetic benefits}

More than the measurement of the air return ratio based on the tracer gas technique, the energetic performance is of interest. A direct comparison of the hot air temperature with and without 

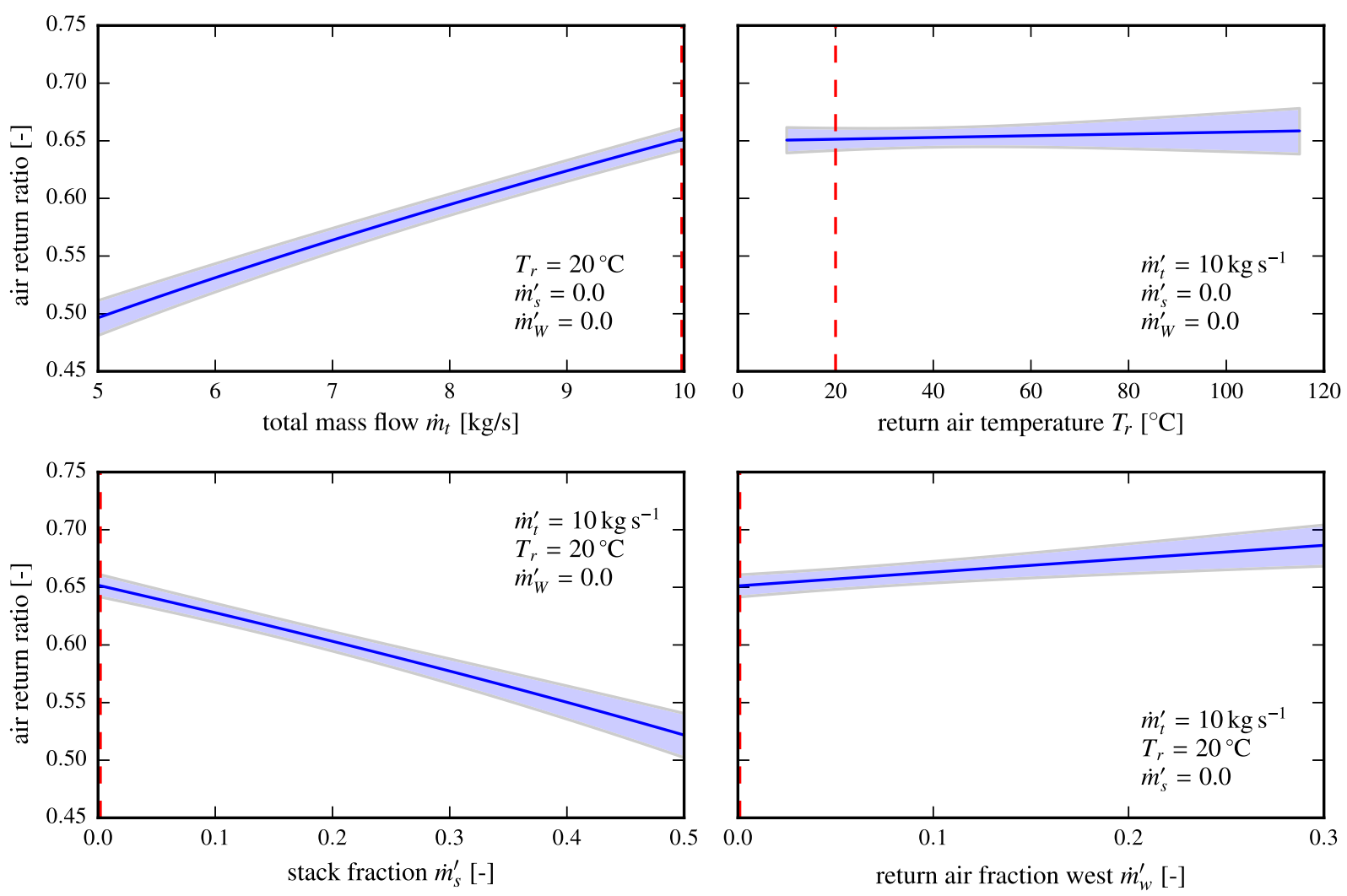

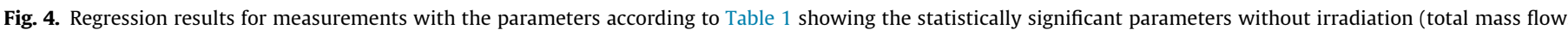

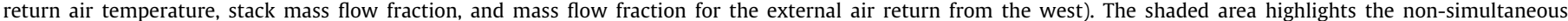

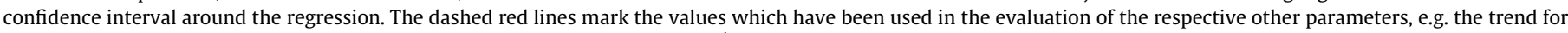
the air return temperature was evaluated for a constant mass flow of $10 \mathrm{~kg} \mathrm{~s}^{-1}$, a stack fraction of 0 , and a fraction of the return air west of 0 .

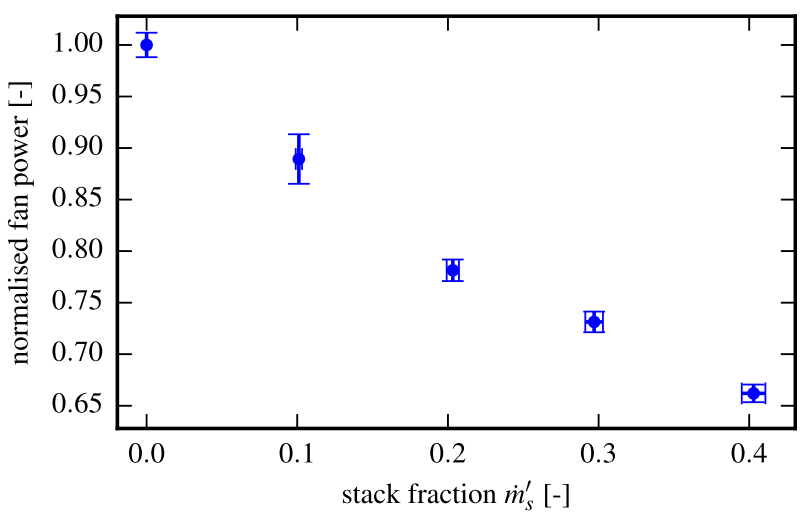

Fig. 5. Parasitic power consumption of the fan normalised to the reference case with stack mass flow fraction $\dot{m}_{s}^{\prime}=0$.

external air return has not been feasible since it has not been possible to obtain stationary conditions for all experiments. Especially the air channels of the external air return system take a long time to heat up so that the temperature of the externally returned air is well below the temperature of the fraction of the air that is blown out through the receiver.

As an indication for the influence of the external air return system the relative temperature distribution across the receiver can be used. The receiver is divided into four subreceivers of equal size for which the hot air temperature has been measured separately (similar to the measurement of the return air temperature, the subreceiver temperatures are also averaged over five individual thermocouples of type $\mathrm{N}$ which are evenly distributed in the hot air pipe). Among the experiments without irradiation have been five experiments with warm return air in the range of $100^{\circ} \mathrm{C}$. In Fig. 6 the mean relative difference of the hot air temperature of each subreceiver compared to the average temperature across the entire receiver is shown for these experiments. Numeric values of the differences are given and also highlighted in colour (dark orange: above average; light orange: below average).

In the base case without external air return (top of Fig. 6) the hot air temperatures of the upper two subreceivers are approximately $4.2 \%$ above average and the temperatures of the bottom subreceivers accordingly $4.2 \%$ below the average. The standard deviation of this mean relative temperature difference is about $0.01 \%$ over the measurement time. The following plot (centre, left) shows the relative distribution when the external air return on the east is opened (illustrated with the arrows on the east - here left side). The temperature of the top subreceivers is still higher than the bottom subreceivers, but more pronounced is the shift from the west to the east. The opposite case with the external air return opened on the west side (centre, right) is almost mirror-inverted. In the bottom row the total mass flow is twice as high as for the previous images. It can be seen, that the temperature differences across the subreceivers are stronger with external air return opened on the east side (bottom, left). With the external air return opened on the bottom (bottom, right) the original shift to the top is reduced but a shift from the east to the west also occurs. This shift to the east can not fully be explained with the current data but it could be due to external effects like wind. 
base case, $\dot{m}_{t}=5 \mathrm{~kg} / \mathrm{s}$
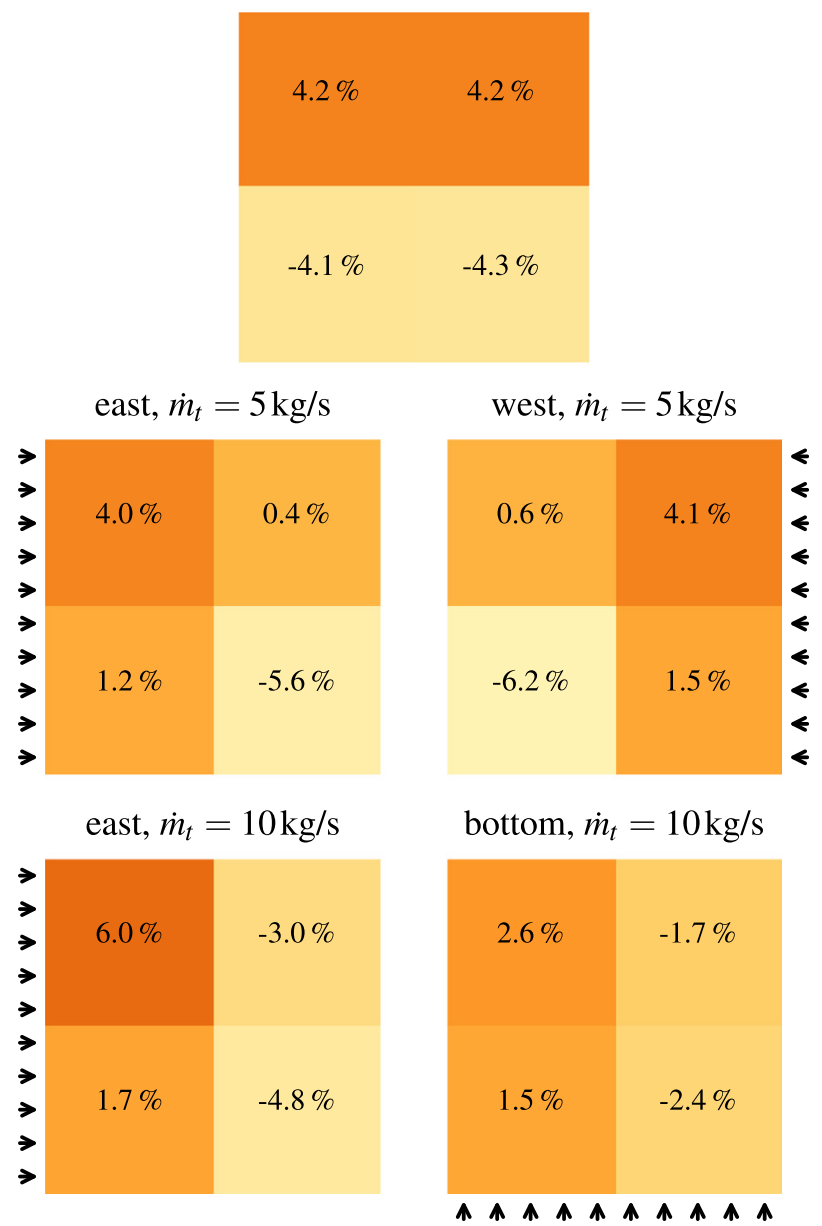

Fig. 6. Relative temperature distribution given in percent deviation from the mean value between the four subreceivers in case of different settings of the external air return. The base case on top reflects the temperature distribution without the use of the external air return system.

\section{Discussion}

As can be seen in Fig. 4, the air return ratio $A R R_{s}$ increases with increasing total mass flow $\dot{m}_{t}$. Although the regression shown suggests a linear trend this result has to be regarded carefully. No experiments have been conducted at intermediate mass flows so that no other behaviour can be deduced from these experiments. However, a similar trend, though much weaker, was reported by Téllez et al. (2004) for their measurements of the air return ratio based on enthalpy flows $A R R_{e}$. No reason for that trend was reported, moreover, a constant value for the air return ratio was instead assumed.

Now that the trend has turned out to be much stronger in the current investigation, an explanation has to be found. However, at the current time, only assumptions can be made trying to explain this trend. One possible explanation is a shift in the air distribution. On the one hand, the receiver is designed in a way that the mass flow being sucked in is larger in the centre where high solar concentration can be expected and lower on the outer rim. On the other hand, the distribution of the return air follows a different pattern, so that locally the ratio of return air to sucked-in air varies. It can now be assumed, that the return air follows the design distribution between the absorber modules at the higher mass flow rate but does not follow it anymore under part load conditions. This could lead to sincere entrainment of ambient air in regions where there is little return air under part load conditions which is equivalent to a local reduction of the air return ratio and thus could also influence the total air return ratio.

Another possible explanation is that external effects like wind don't affect the air return ratio as much when the mass flow through the absorber is increased because the momentum of the outgoing air is increased.

Concerning the stack mass flow fraction, the decrease of the air return ratio with increasing fraction is not surprising - less air is returned to the receiver, so less can be sucked in again. However, it is important to note that the reduction is disproportional, since a larger fraction of the air returned to the receiver is sucked back in. Considering the flow around the absorber modules described in the beginning, it can be assumed that the internal heat exchange from hot to warm air is reduced due to a reduction of the warm air flow so that the hot air looses less energy. At the same time the local air return ratio increases so that the energetic losses are reduced. Although the external air return does not significantly alter the overall air return ratio (the only statistically significant variable is $\dot{m}_{W}^{\prime}$ which also has only little influence), the above suggest a significant energetic improvement.

Under irradiation the trends could not be clearly identified which can be seen in the difference between the statistical evaluation and the direct comparison of similar settings. Since under irradiation the warm air temperature has almost always been higher than without irradiation it could be, that during regression the effects of irradiation and warm air temperature could not be clearly differentiated. Moreover, the irradiation as such might not be an appropriate parameter to include in the regression, but rather surface temperatures of the receiver should be included since the air return ratio is only affected by the air flow distribution which in turn is influenced by the temperature distribution.

\section{Conclusion and outlook}

With the measurements with external air return at the Solar Tower Jülich the key factors influencing the air return ratio and thereby the receiver efficiency have been identified. Most important, an increase in the total mass flow causes a significant increase in the air return ratio. The influence of the return air temperature and the external air return system on the integral air return ratio is not as pronounced. Further investigations at the Solar Tower Jülich with a wider set of parameters are neccessary in order to evaluate the exact trends quantitatively. Lab-scale experiments or CFD simulations would be useful in order to identify the physical cause for the identified trends.

It has been shown that the local air return ratio of the fraction blown out through the receiver rises when a part of the air is returned externally. Due to this effect a larger fraction of the enthalpy carried with the return air is recycled and thus an increase in efficiency can be achieved.

The above mentioned trends seem to persist under irradiation but clearly, a more comprehensive study for the effect of irradiation is needed.

All experiments with the external air return system showed a significant reduction of the parasitic losses at the fan due to a reduction of the pressure losses with the external air return system. This reduction of the parasitic losses can result in an increase of the annual yield of more than $10 \%$ and is thus one of the major levers to increase performance of open volumetric receivers.

\section{Acknowledgements}

This work was supported by the Federal Ministry for Economic Affairs and Energy on the basis of a decision by the German Bundestag, reference number 0325443B. 


\section{References}

Ahlbrink, N., Andersson, J., Diehl, M., Pitz-Paal, R., 2013. Optimization of the mass flow rate distribution of an open volumetric air receiver. J. Solar Energy Eng. 135 (4), 041003

Anderson, B., 2013. Brayton-cycle baseload power tower CSP system. Tech. Rep. DEEE0003587, Wilson Solarpower, 150 Lincoln St, Suite 3C, Boston, MA 02111.

Ávila-Marín, A.L., 2011. Volumetric receivers in solar thermal power plants with central receiver system technology: a review. Solar Energy 85, 891-910.

Becker, M., Fend, T., Hoffschmidt, B., Pitz-Paal, R., Reutter, O., Stamatov, V., Steven, M., Trimis, D., 2006. Theoretical and numerical investigation of flow stability in porous materials applied as volumetric solar receivers. Solar Energy 80 (10), 1241-1248.

Buck, R., Bräuning, T., Denk, T., Pfänder, M., Schwarzbözl, P., Téllez, F., 2002. Solarhybrid gas turbine-based power tower systems (REFOS). J. Solar Energy Eng. $124,8$.

Capuano, R., Fend, T., Hoffschmidt, B., Pitz-Paal, R., 2015. Innovative volumetric solar receiver micro-design based on numerical predictions. In: Proceedings of the ASME 2015 International Mechanical Engineering Congress and Exposition. No. IMECE2015-50597. ASME, Houston, Texas. November 13-19.

Fend, T., Hoffschmidt, B., Pitz-Paal, R., Reutter, O., Rietbrock, P., 2004. Porous materials as open volumetric solar receivers: experimental determination of thermophysical and heat transfer properties. Energy 29 (5), 823-833.

Flesch, R., Grobbel, J., Stadler, H., Uhlig, R., Hoffschmidt, B., 2016. Reducing the convective losses of cavity receivers. In: AIP Conference Proceedings, vol. 1734 (1).

Hoffschmidt, B., Téllez, F., Valverde, A., Fernández, J., Fernández, V., 2003. Performance evaluation of the 200-kWth HiTRec-II open volumetric receiver. J. Solar Energy Eng. 125 (1), 87-94.

Jang, H., Kim, T., Park, M., 2012. The first concentrating solar power project in korea. In: Proceedings of the 18th SolarPACES Conference, p. 23826.

Koll, G., Schwarzbözl, P., Hennecke, K., Hartz, T., Schmitz, M., Hoffschmidt, B., 2009. The solar tower Jülich-a research and demonstration plant for central receiver systems. In: Proceedings of the 15th SolarPACES Conference.

Kribus, A., Doron, P., Rubin, R., Reuven, R., Taragan, E., Duchan, S., Karni, J., 2001 Performance of the directly-irradiated annular pressurized receiver (DIAPR) operating at 20 bar and $1200{ }^{\circ} \mathrm{C}$. J. Solar Energy Eng. 123 (1), 10-17.
Kribus, A., Ries, H., Spirkl, W., 1996. Inherent limitations of volumetric solar receivers. J. Solar Energy Eng. 118 (3), 151.

Maldonado Quinto, D., 2016. Konvektive Verluste an offenen volumetrischen Solarstrahlungsempfängern. Ph.D. thesis, RWTH Aachen, in German.

Marcos, M.J., Romero, M., Palero, S., 2004. Analysis of air return alternatives for CRStype open volumetric reciever. Energy 29, 677-686.

McMillan, O., 1984. Investigation into the feasibility of an air curtain for a solar central receiver, final report. Tech. rep., Nielsen Engineering and Research, Inc., Mountain View, CA (USA).

NIST/SEMATECH, 2016. e-handbook of statistical methods. <http://www.itl nist.gov/div898/handbook/>.

Pitz-Paal, R., Hoffschmidt, B., Böhmer, M., Becker, M., 1997. Experimental and numerical evaluation of the performance and flow stability of different types of open volumetric absorbers under non-homogeneous irradiation. Solar Energy 60 (3-4), 135-150.

Schwarzbözl, P., Hack, U., Ebert, M., 2011. Improvement of ceramic absorber material for open volumetric receivers. In: 17th SolarPACES Conference. Granada, Spain.

Tan, T., Chen, Y., Chen, Z., Siegel, N., Kolb, G.J., 2009. Wind effect on the performance of solid particle solar receivers with and without the protection of an aerowindow. Solar Energy 83, 1815-1827.

Téllez, F., Romero, M., Heller, P., Valverde, A., Reche, J.F., Ulmer, S., Dibowski, G., 2004. Thermal performance of SolAir $3000 \mathrm{kWth}$ ceramic volumetric solar receiver. In: 12th SolarPACES International Symposium on Concentrated Solar Power and Chemical Energy.

Tiddens, A., 2017. Qualification methods for open volumetric air receivers with recirculation Ph.D. thesis. RWTH Aachen.

Tiddens, A., Röger, M., Stadler, H., Hoffschmidt, B., 2016. A tracer gas leak rate measurement method for circular air circuits. Flow Measure. Instrum. 47 (March), 45-53.

Tiddens, A., Röger, M., Stadler, H., Hoffschmidt, B., 2017. Air return ratio measurements at the solar tower jlich using a tracer gas method. Solar Energy 146 (Apr), 351-358. 